\title{
GAIA Level 1 Low Birth Weight
}

National Cancer Institute

\section{Source}

National Cancer Institute. GAlA Level 1 Low Birth Weight. NCI Thesaurus. Code C128725.

GAIA Level 1 Low Birth Weight is defined by one of the two following criteria: first, a newborn infant is weighed within 24 hours of birth; an electronic scale that is graduated to 10 grams is used; the scale is calibrated at least once a year; the scale is placed on level, hard surface; the scale is tared to zero grams; AND the birth weight recorded is less than 2500 grams; OR second, a birth weight is recorded as less than 2500 grams as assessed per the health care facility's standard operating procedure, which fulfills criteria 1 to 5 of diagnostic level of certainty one. 